AGRICULTURE AND BIOLOGY JOURNAL OF NORTH AMERICA

ISSN Print: 2151-7517, ISSN Online: 2151-7525, doi:10.5251/abjna.2013.4.2.122.125

(C) 2013, ScienceHuß, http://www.scihub.org/ABJNA

\title{
Impact of host's diet and parasite intensity on Morphology of Moniezia expansa
}

\author{
*J.A. Kuchai, Fayaz Ahmad, M.Z. Chishti and Hidayatullah Tak \\ Post Graduate Department of Zoology, University of Kashmir, Srinagar- 190006 \\ *Email: kuchayjk@gmail.com
}

\begin{abstract}
The present study is a part of the helminthological study conducted on ruminants of Ladakh for the time period of one year. In the present study impact of diet of the host and intensity of the parasite on Morphology of a Cestode (Moniezia expansa) was taken into consideration for which postmortem examination of slaughtered host animals belonging to different age groups and of either sex feeding on different diets were carried out and the parasite/s recovered were processed and were subjected for the study of morphology and morphometry. It was observed that diet and intensity was having a relation with morphology and morphometry of the parasite. In case of higher intensity the size of parasite was comparatively small as compared to the specimens with low intensity, so was the case with respect to diet of the host it was observed that the parasites recovered from the host animals which feed on highly nutritive food were larger in size as compared to those specimens recovered from the hosts which feed on average or below average food. The parasite being reported for the first time from this region has been briefly redescribed with some intraspecific variations.
\end{abstract}

Keywords: Diet, Intensity, Morphology, Morphometry, Moniezia expansa, Ladakh

\section{INTRODUCTION}

Helminthiasis has been found as one of the causes of the production losses, which arise primarily through severe weight loss, poor meat, milk and wool production, carcase and offal condemnation and impaired reproductive performance, etc. and has a direct effect on economy and biodiversity of this region. If this loss is to be reduced, then steps need to be taken to control these parasitic infections which need detailed information regarding the species of parasite present, intensity of the infection, the host to be infected, effect of sex, age, season, breed, and various environmental factors in a particular region. Among the various cestode parasites $M$. expansa is one among the most occurrence species, the parasites inhabit the intestines of the host and its morphology is so good to adjust successfully in this environment. Although the parasite does not harm the host to a greater extent to cause a serious problem but in heavily infected and small aged animals the parasite could prove harmful to the host by utilizing the hosts digested food not only resulting in malnutrition but also makes host weak and more susceptible to other diseases by decreasing its immunity.

Although a lot of work has been done on various aspects of this parasite species by various authors from different corners of the World (Baylis, 1935; Anantaraman, 1951; Borthakur and Das, 2006; Fukui, 1959) as well as from Jammu and Kashmir region (Ayesha et al., 2008, Muzaffar, 2010) of the Jammu and Kashmir state however no work has been done in Ladakh the third region of the same state where ruminants are comparatively more important because it is comparatively poor in other resources.

\section{MATERIALS AND METHODS}

Different parts of the study area were surveyed and gastrointestinal tracts of slaughtered animals were collected and processed for detection of parasites. The various organs of GIT were separated from each other as well as from suspensor ligaments and were placed individually in shallow plastic jars containing normal saline solution $(0.85 \%)$, The small and large intestines were firstly pressed from one end to other and the content was taken into a large plastic jar which was latter examined for collection of cestodes which come out (if present) by pressing mechanism and latter a longitudinal incision was given to the intestines to open them for further observations. The parasites thus collected were fixed in Carnoy's fixative and preserved in $70 \%$ alcohol; the preserved material was taken out of the preservative and was stained in aceto alum carmine. After staining the material was subjected to dehydration by passing it 
through various grades of alcohol viz., $30 \%, 50 \%$, $70 \%, 90 \%, 100 \% \mathrm{I}$ and $100 \%$ II. The time duration in each grade was 5-10 minutes. After complete dehydration the material was transferred to a clearing agent (xylene in this study). The dealcoholized material was mounted in canadabalsam or DPX on glass slides for a detailed morphological study. The drawings of the parasites or parts of parasites were made with the help of prism type camera lucida for morphometry. Identification of parasites was done on the basis of various morphological and morphometric characters (Bambroo 1969; Bali 1970; Soulsby 1982). The climatological data was provided by government meteorological department of Ladakh.

\section{RESULTS AND DISCUSSION}

The present study show that there was a considerable difference in size of the parasites with respect to the diet of the host. It was observed that the parasites were usually larger in those host animals which feed on highly nutritive diet as compare to those who feed on comparatively low standard diet while as the intensity was in a reversed order that higher in case of later ones and lower in former ones. Similarly an association was observed between intensity and morphometry of the parasites as it was observed that in case of higher intensity the size of parasite was comparatively small as compared to the specimens with low intensity. The parasite being reported for the first time from some of the hosts of this region is briefly described with some intraspecific variations as under.

Description: Comparative characteristics have been given in Table 1. The specimens are white in colour, Table 1. Comparative characteristics of Moniezia expansa Rudolphi, 1891

\begin{tabular}{|c|c|c|c|c|}
\hline Particulars & Bambroo (1968) & $\begin{array}{c}\text { Bali } \\
(1970)\end{array}$ & Soulsby (1982) & $\begin{array}{c}\text { Present } \\
\text { Specimens }\end{array}$ \\
\hline Total length & $2-4 m$ & $200-400 \mathrm{~cm}$ & $450-600$ & $523(453-593)$ \\
\hline Max. breadth & $5-10$ & $5-11$ & $1.6 \mathrm{~cm}$ & $1.3(1.2-1.4)$ \\
\hline Scolex & $0.6-0.9$ & $0.65-0.92$ & $0.36-0.8$ & $0.91 \times 1.06(0.85-0.97 \times 1.03-1.09)$ \\
\hline Suckers & $0.25-0.32$ & $0.25-0.35$ & $\cdots \cdots$ & $\begin{array}{c}0.40 \times 0.37 \\
(0.38-0.42 \times 0.35-0.39)\end{array}$ \\
\hline Mature Segment & $\begin{array}{l}1.1-1.3 x \\
4.1-4.5\end{array}$ & $\begin{array}{c}4.4-4.5 x \\
1.2-1.4\end{array}$ & $\cdots \cdots$ & $\begin{array}{c}0.96 \times 3.5 \\
(0.93-0.99 \times 3.0-3.9)\end{array}$ \\
\hline Gravid Segment & $\begin{array}{c}0.75-0.82 x \\
5.25-5.3\end{array}$ & $0.75-0.9 \times 5.5-5.6$ & $\ldots$. & $0.55 \times 3.96(0.048-0.062 \times 3.05-4.87)$ \\
\hline Egg & $70-90 \mu$ & $70-90$ & $56-67 \mu$ & $\begin{array}{c}0.054 \times 0.075(0.068-0.082 x \\
0.051-0.057)\end{array}$ \\
\hline Host & Sheep & Sheep & Domestic animals & Ruminants \\
\hline Locality & Kashmir & Kashmir & London & Ladakh \\
\hline
\end{tabular}

tapering, and measures $453-593 \mathrm{~cm}$ in length $1.2-1.4$ $\mathrm{cm}$. in width. The scolex was $0.85-0.97 \mathrm{~mm} \times 1.03-$ $1.09 \mathrm{~mm}$ in diameter; with prominent four suckers measuring $0.38-0.42 \mathrm{~mm} \times 0.35-0.39 \mathrm{~mm}$. The scolex leads into neck followed by segments. The mature segments contain reproductive organs and are broader (3.7-3.9 $\mathrm{mm})$ than long $(0.93-0.99 \mathrm{~mm})$ and each contain two sets of genital organs. Gravid segments measures $0.048-0.062 \mathrm{~mm}$ by $3.05-4.87$ $\mathrm{mm}$. The ovaries and the vitelline glands form a ring on either side, median to the longitudinal excretory canals, while the testes are distributed through out the central field or they may be concentrated towords the sides. At its posterior border each proglottid contains a row of interproglotidal glands, arranged around small pits. The eggs are somewhat triangular in shape, containing a well-developed pyriform apparatus, and measures 0.068-0.082 mm X0.051$0.057 \mathrm{~mm}$ in diameter.

Remarks: The morphological studies of the present specimens confirmed their identification to Moniezia expansa as described by (Bambroo 1969; Bali 1970; Soulsby 1982) on the basis of various morphological characters as body length, maximum width, and size of suckers, scolex, presence of two sets of reproductive organs per mature segment, and presence of continuous band of interproglotids. However some intraspecific variations in size ratio of body and various other body organs were recorded in the present specimens presented in table given above. It is therefore assigned to Moniezia expansa Rudolphi, 1891.This is the first report of this species from this Ladakh region. 


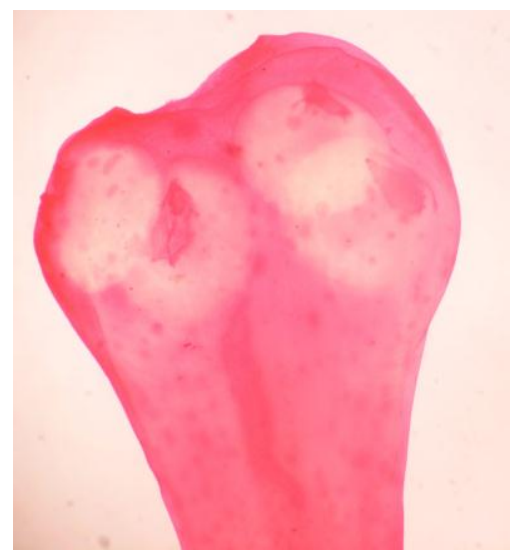

Pmg. 1

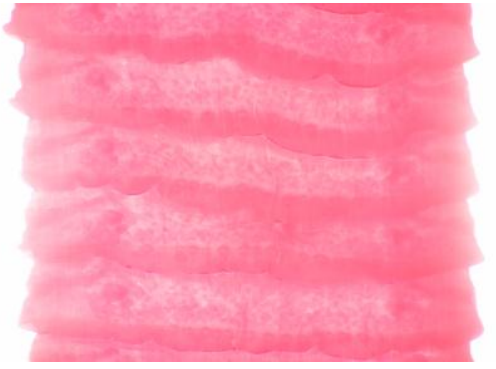

Pmg. 2

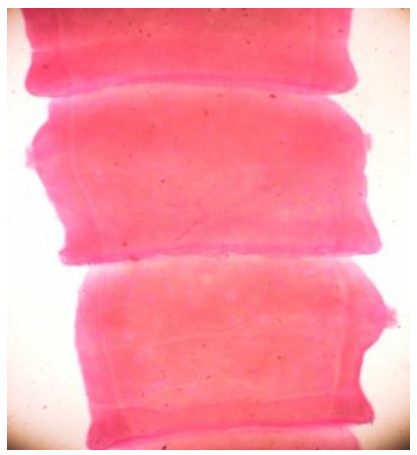

Pmg. 3

1-3. Moniezia expansa Rudolphi, 1891 Pmg = photomicrograph
(1) Scolex
(2) Mature segment
(3) Gravid segment

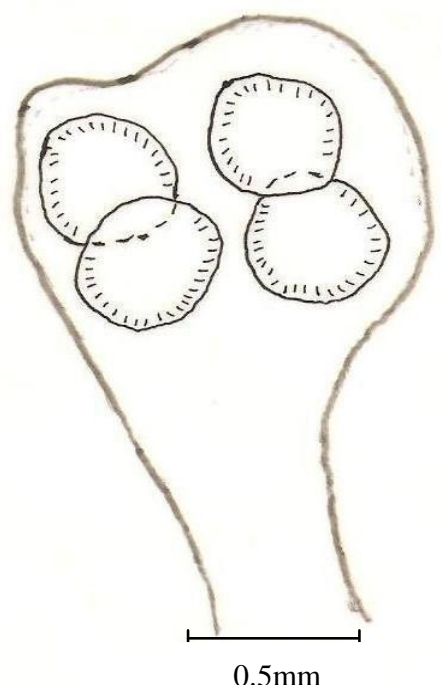

Fig. 12

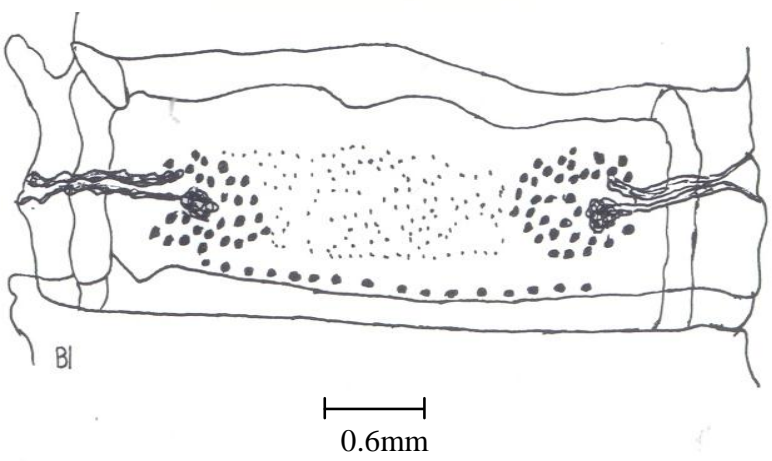

Fig. 13

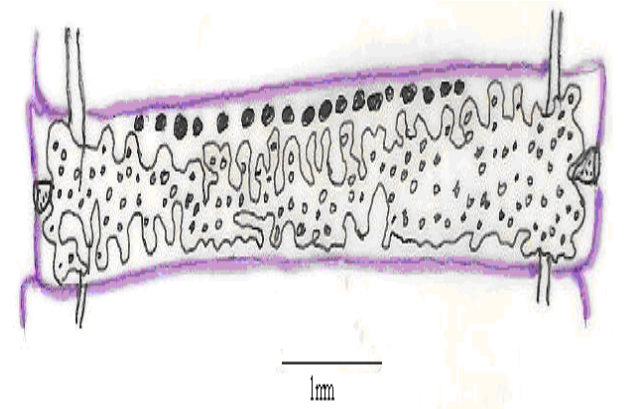

Figs.12-15. Moniezia exjägnsa Rudolphi, 1891
(1) Scolex
(2) Mature segment
(3) Gravid segment (4) Egg 


\section{CONCLUSION}

From the present study it is obvious that diet of the host as well as intensity of the parasite species have a direct impact on the morphology of the parasite species M. expansa in this study.

\section{ACKNOWLEDGEMENT}

The authors would like to thank the accommodators, bouchers, farmers, veterinary hospital staff members of the Ladakh for providing their whole hearted support during the study. Thanks are also due to $\mathrm{G}$. M. Kuchay for his financial support.

\section{REFERENCES}

Ayesha A, Khan AR (2008). Prevalence of endohelminth parasites in sheep of Doda district of Jammu and Kashmir state. Proceedings of $2^{\text {nd }}$ JK Science Congress.

Anantaraman M (1951). The development of Moneizia, the large tapeworm of domestic ruminants. Science and Culture, 17(4): 155-157.

Bali HS (1976). A survey of helminth parasites of sheep (Ovis aris) in Jammu and Kashmir. Journal of Animal Health Production, 4: 25-32.

Baylis HA (1935). Note on the cestode Moniezia (Furhmanella) Transvoalensis (Baer, 1925). Mem. Ind. Mus. 9(8): 248-251.

Bambroo N (1970). On two species of Gastrothylax Poirier, 1883 from sheep in Kashmir. Kashmir Science, 7(1-2): 147-155.

Belem AMG, Nikiema ZL, Sawadogo L, Dorchies P (2000). Sheep gastro-intestinal parasites and risk of parasite infection from pasture during the rainy season in the central area of Burkina Faso. Revue de Medecine Veterinaire, 151(5): 437-442.
Borthakur SK, Das MR (2006). Incidence of Monieziasis in cattle and buffalo calves of Guwahati. Journal of Veterinary Parasitology, 20(1): 97-98.

Fukui C (1959). Incidence of Moniezia in small ruminants and role of its intermediate host. Bull. Anim. Hith. Prod. Afr. 24(5): 55-60.

Gupta SK, Mathur MB (1968). Intestinal parasitic infections in young buffalo calves and anti - helmintic treatment. Indian Vet. Med. J. 14(3): 194-197.

Kenddell SB, (1965). Relationship between the species Fasciola and their molluscan hosts. Adv. Parasitol. 3: 59-98.

Muzaffar R, (2010). Helminth Parasites in Ruminants of Jammu M. Phil. Dissertation, Department of Zoology, University of Kashmir, Srinagar.

Makhdoomi DM, Nasreen S, Banday SD, Moulvi BA (1995). Incidence of different Ovine gastrointestinal parasites in Kashmir. Ind. Vet. J. 72(8): 898-900.

Raina MK (1973). Incidences of infection of sheep and goats with Avitellina Gough, 1911, Stilesia Railliet,1882 and Moniezia Blanchard, 1891 in Kashmir. J. Sci. Univ. Kashmir, 1(1-2): 59-62.

Schimdt GD (1986). Hand book of Tapeworm Identification. CRC Press, Inc. Boca Raton, Florida, 675 pp.

Soulsby EJL (1982). Helminths, Arthopods and Protozoa of Domesticated animals. Bailliere,Tindal and Cassel,London,809 spp.

Taylor EL (1928). Moneizia a genus of cestode worms and the proposed reduction of its species to three. Proc. $U$. S. Nat. Mus. Wash. LXXIV, 1-9.

Ternopolskaya LD (1984). Variability of Fasciola hepatica L., 1785 in different hosts. Bulletin Vsesoyuznogo Instituta Gel. Mintologil Im. K. I. Skrybin, 38: 47-51. 